\title{
ELEMENTOS DO COMPORTAMENTO HUMANO COMO FATORES PARA OS CAMINHOS DA FELICIDADE
}

\author{
ELEMENTS OF HUMAN BEHAVIOR AS FACTORS FOR THE PATHS TO HAPPINESS
}

\author{
Fabricio Rigui Botega ${ }^{1}$
}

RESUMO: A felicidade é e sempre será uma busca incansável do ser humano. Ao longo da história da humanidade foi debatida e conceituada por vários filósofos, estudiosos e por quem não se cansa de tentar traduzir em palavras este conceito tão importante para a realização das pessoas. Sabe-se que para o encontro ou o alcance da felicidade são necessários alguns elementos importantes, que se bem entendidos, compreendidos e vividos podem resultar neste objetivo realizado, porém é preciso que haja mudanças pessoais e interpretação de algumas atitudes ao longo da vida. $O$ objetivo principal do trabalho que segue, utilizando de uma metodologia de pesquisa bibliográfica e investigação em diversas fontes, com a utilização de diversos recursos de pesquisa, foi o de demonstrar os caminhos que contribuem para que talvez se descubra o que realmente é felicidade. Não somente uma, mas várias são as abordagens e os aspectos que contribuem para a descoberta da felicidade, desde as relações pessoais, a interpretação de situações ao longo da vida, a relação espiritual, o conhecimento sobre si próprioe o quanto cada um destes elementos representam e significam para cada pessoa. Entender a influência das necessidades apresentadas por Maslow contribui para este encontro do bem estar, do sentir-se bem, pleno, equilibrado e realizado, apresentando a conexão entre os mais diversos fatores e ações que interferem neste caminho e, independente se for vida pessoal ou profissional, a satisfação destas necessidades torna-se uma importante ferramenta para o alcance e concretização do encontro do bem estar, da plenitude e da realização intrínseca que leva o indivíduo ao encontro da felicidade. Portanto, felicidade pode depender de um conjunto de elementos e fatores, mas o importante é que ela, em dado momento acaba por existir, fazendo com que o indivíduo por si só tenha esta percepção e curta o momento feliz.

Palavras-Chave: Felicidade. Elementos. Indivíduo.

ABSTRACT: Happiness is and always will be a tireless pursuit of human beings. Throughout human history, it has been debated and conceptualized by several philosophers, scholars and by those who never tire of trying to translate into words this concept that is so important for people's achievement. It is known that, in order to find or reach happiness, some important elements are needed, which if well understood, understood and lived, can result in this objective being achieved, but there must be personal changes and interpretation of some attitudes throughout life. The main objective of the work that follows, using a methodology of bibliographic research and investigation

\footnotetext{
${ }^{\mathrm{I}}$ Professor mestre em Ciência da Educação, MBA em Negociação e Consultoria; Especialista em Gestão Empresarial; Especialista em Docência Superior e Gestão Educacional; Formação Professional \& Self Coaching; Bacharel em Administração; Licenciado em Geografia. E-mail: ffrighir979@gmail.com.
} 
in different sources, with the use of different research resources, was to demonstrate the ways that contribute to perhaps discovering what happiness really is. Not only one, but several are the approaches and aspects that contribute to the discovery of happiness, from personal relationships, the interpretation of situations throughout life, the spiritual relationship, knowledge about oneself and how much each of these elements represent and mean to each person. Understanding the influence of the needs presented by Maslow contributes to this meeting of well-being, feeling good, full, balanced and fulfilled, presenting the connection between the most diverse factors and actions that interfere in this path and, regardless of whether it is personal life or professional, the satisfaction of these needs becomes an important tool for achieving and implementing the encounter of well-being, fullness and intrinsic fulfillment that leads the individual to find happiness. Therefore, happiness can depend on a set of elements and factors, but the important thing is that it, at a given moment, ends up existing, making the individual by himself have this perception and enjoy the happy moment.

Keywords: Happiness. Elements. Individual.

\section{INTRODUÇÃO}

Felicidade é uma discussão que leva há vários cenários e definições. Entender que para cada pessoa o significado de felicidade traduz conceitos, experiências e representatividades diferentes é a grande questão, trazendo discussões em torno do assunto, possibilitando reflexões e a compreensão que as sensações estão diretamente ligadas às ações desempenhadas no cotidiano.

De certa maneira a apresentação deste tema também compreende aspectos relacionados à timidez, confiança, dinamismo, diálogo e qualidade de vida de muitas pessoas, pois discute e provoca reflexões sobre o sentir-se e estar bem, interrogações sobre o que realmente importa para o viver diário, entre outros.

Discutir ou abordar a temática sobre felicidade remete à flexibilidade deste assunto, pois, o mesmo pode abranger tantas outras questões que integram este conceito e, desde a antiguidade muitos filósofos se propuseram a tratar e definir, de acordo com seus pontos de vista, o tema.

O que se sabe, de uma maneira geral, é que felicidade remete ao bem-estar, ao sentir-se bem, estar bem consigo e com os outros, porém é uma busca incessante à este equilíbrio, visto que há tantas situações que permeiam a vida real e que provocam oscilações de humor, de motivações, de baixa ou alta estima.

Desta forma, um dos pontos abordados neste artigo serão os conceitos, sem entrar em discussões mais aprofundadas sobre a visão de cada filósofo, que definiram a felicidade ao longo da história.Assim também será abordado no desenvolvimento deste artigo o autoconhecimento, a 
empatia, o perdão e a gestão das emoções, demonstrando a influência de cada um destes pontos no equilíbrio e bem-estar pessoal.

Ao escolher este tema para discorrer a respeito, objetivou-se demonstrar os conceitos que envolvem o mesmo, os pontos chave que compõem a chamada felicidade e o quanto cada um tem representatividade no cotidiano do ser humano.

Como fontes de pesquisa foram utilizadas várias bibliografias que abordam o assunto em questão, caracterizando-se assim a metodologia adotada por uma pesquisa bibliográfica, onde procurou-se trazer, de uma maneira muito simples e direta, conceitos, discussões e pontos de vista dos autores consultados e, que remetem à uma melhor compreensão do quanto existem um conjunto de situações que levam ao encontro da felicidade.

Então, entende-se que trazer uma abordagem do conceito de felicidade e dos elementos que a compõem, pode colaborar para algumas reflexões sobre o quanto cada um dos elementos interfere e significam na vida do ser humano, influenciando em seus comportamentos e atitudes.

\section{SOBRE OS CONCEITOS DE FELICIDADE}

Desde a antiguidade a felicidade é debatida em investigações, trazendo discussões e reflexões entre vários filósofos desde o século IV antes de Cristo. Neste período, os grandes filósofos definiam a felicidade de acordo com seus pontos de vista, traduzindo em seus conceitos, sentimentos e emoções do que acreditavam ser a felicidade.

No grego, a felicidade é definida como“eudaimonia", tendo o prefixo "eu",o significado de "bom”, e de "daimon", “demônio", representando de acordo com este conceito que, os seres humanos tinham a companhia de um tipo de semi-deus ou de gênio, expressando que para que houvesse a felicidade era preciso ser acompanhado por um "bom demônio", o qual estava diretamente relacionado a sorte de cada indivíduo.Por sua vez, a pessoa que tivesse a companhia de um "mau demônio" só teria infelicidade.

Já Sócrates (469 a.C. - 399 a.C.) cria o paradigma que diz que a busca pela felicidade é tarefa individual, pregando que o caminho para a condução desta condição, seria a filosofia,postulando, ainda que, a felicidade não se correlacionava somente à satisfação e atendimento dos desejos e necessidades do corpo. Para ele, não somente o corpo era o homem completo, mas sim este também possuía a alma.Entretanto, para que a felicidade 
existisse era necessário ter o bem da alma, sendo que esta seria alcançada por comportamentos, atitudes e também por uma conduta correta, virtuosa e justa.

Para o grande discípulo de Sócrates, Platão (427 a.C. - 347 a.C.), foilevando adiante a especulação filosófica e considerava que tudo possui uma função. Assim, a função do olho é proporcionar a visão, a do ouvido proporcionar a audição e a função que a alma detém é ser justa e virtuosa e, esta exercendo a justiça e a virtude, se apossa da felicidade.

Aristóteles (384 a.C. - 322 a.C.), na mesma linha de pensamento dos conceitos de Platão, colabora que a felicidade é compreendida com ações da alma segundo a virtude, queé o bem supremo, que tem um fim em si mesmo, sendo almejado por todos. O que constitui a felicidade são as ações virtuosas, e as atividades viciosas conduzem o contrário. (BARBOSA, 2018)

O período em que a cultura grega era dominante no mundo antigo chamado de cultura helênica ou helenismo e, que teve prosseguimento no pós morte do imperador Alexandre, o Grande, pode-se citar entre os filósofos de destaque, Epicuro (34I a.C. - 269 a.C.), que considera a felicidade ligada diretamente ao prazer. Para ele,o prazer era fundamental para a felicidade, dividindo este prazer de duas formas:

A primeira considera o prazer estável, ou seja, com a ausência de perturbações e

dores. À esta forma de prazer não considera-se sofrimento, fazendo com que o homem mantenha-se em paz e, desta maneira, atinja a felicidade.

A segunda forma, afirma que o homem pode se tornar um escravo do prazer, o que o leva a viver uma vida desassossegada e que não condiz com a felicidade. Para Epicuro esta forma de prazer estaria ligada somente a alegria e ao gozo.

$\mathrm{Na}$ Idade Moderna, a felicidade voltou a ser debatida entre os filósofos do período. $\mathrm{Na}$ mudança dos séculos i7 e I8, John Locke (1632 - 1704) e Leibniz (I646 -1716), constatam a felicidade relacionada com prazer, este considerado um prazer duradouro.

Décadas depois, em sua obra "Crítica da razão prática”, Immanuel Kant (1724 I804), filósofo iluminista, define felicidade como uma condição do ser racional no mundo, para quem, ao longo da vida, tudo acontece de acordo com o seu desejo e vontade. (OLIVIERI, 2009)

Entretanto, Kant pondera que a felicidade, estando na esfera do prazer e desejo, não tem nada a ver com Ética e, desta maneira não merece investigação filosófica, fato que sua 
ponderação acabou convencendo a muitos, que a partir daí fez com que a felicidade desaparecesse de obras filosóficas.

No entanto, o filósofo alemão, Arthur Schopenhauer (I788 - I860), influenciado por Platão e Kant, conceitua a noção da felicidade como a "satisfação sucessiva de todo o nosso querer" e afirma que a tendência a ela, por um lado, coincide completamente com a nossa existência - cuja essência é a Vontade de viver - mas por outro, é revelada pela experiência como o nosso maior erro e desilusão. (GERMER, 20II)

No século I9, o tema felicidade volta a ser abordado por escritores e filósofos deste período, que trazem à tona a discussão. Nietzsche (1844-190o), filósofo, escritor e crítico alemão, define a felicidade como sendo frágil e volátil, pois, esta só é possível ser sentida em determinados momentos e, se fosse vivenciada ininterruptamente, ela não teria valor, pois só se percebe felicidade por meio da comparação.

No contexto da filosofia anglo-saxônica, o inglês Bertrand Russell (1872 - 1970), em sua obra "A conquista da felicidade", cita que para ter felicidade é preciso eliminar o egocentrismo, concluindo, por meio do método de investigação lógica, que a criação de relacionamentos e vários outros interesses, é necessário para ser feliz.

Diante de tantas abordagens sobre os conceitos e discussões da felicidade, é perceptível que esta continua sendo um tema que provoca várias reflexões, permeando sua definição em pleno século 2I. Assim, Cortella (202I) define:

Felicidade é uma vibração intensa. É o momento em que eu sinto a vida em plenitude dentro de mim e quero que aquilo se eternize. Felicidade é a capacidade de ser inundado por uma alegria imensa por aquele instante, por aquela situação. Aliás, felicidade não é um estado contínuo... Felicidade é uma ocorrência eventual. Felicidade é sempre episódica. É você sentir a vida vibrando, seja num abraço, seja na realização de uma obra, seja numa situação em que seu time vence, seja porque algo que você fez deu certo, seja porque você ouviu algo que quis ouvir....É claro que aquilo não tem perenidade. Aliás, a felicidade, se marcada, pela perenidade seria impossível. Afinal de contas, nós só temos a noção de felicidade pela carência. Se eu tivesse a felicidade como algo contínuo eu não a perceberia. Nós só sentimos a felicidade porque ela não é contínua: isto é, ela não é o que acontece o tempo todo em todos os modos.

Por sua vez, o professor Clóvis de Barros Filho, escreve que felicidade é aqueleinstante de vida que vale a pena ser vivido. É autoconhecimento, gratidão e propósito. Ser feliz é estar pleno no aqui e no agora. Felicidade é estar bem com seu espírito, mente e corpo.É estar em sintonia com seus valores, decisões e atitudes, com o que você pensa, fala e faz. (2019) 
Já o professor e escritor Leandro Karnal define a felicidade como um processo de construção histórica que depende de nossas escolhas feitas durante a vida... (2020)

Filósofo, professor e escritor, Luiz Felipe Pondé (2020), diz que felicidade é uma busca constante do ser humano e depende de vários fatores, aliás existem várias formas de felicidade.

Diante de todos estes pontos de vista e conceitos percebe-se que para muitos, felicidade, pode ser um estado de espírito, um momento ou outro fator, porém pode-se considerar que há muitos outros elementos que envolvem a busca constante e o encontro com ela. A felicidade torna-se uma temática complexa com infindáveis abordagens e contínuos estudos, pesquisas e análises.

\section{AS LEIS DA ESPIRITUALIDADE}

O entendimento que "todos os acontecimentos têm sua hora e o momento certo para acontecer", sempre traz discussões em volta deste tema, pois, muitas pessoas compreendem que tudo pode ser mudado ou alcançado de acordo com a vontade, o empenho, a entrega, o compromisso e a força empregada para tal feito, inclusive a felicidade.

De fato, esta é uma verdade! A busca pela realização pessoal e alcance de objetivos depende do esforço e do quanto cada pessoa, realmente almeja algo, porém independente de rótulos, posições sociais, raças, credos e escolhas diversas, é preciso aceitar muitos acontecimentos para ser feliz.

As leis da espiritualidade ensinadas na Índia, segundo seus princípios, conduzem ao amor, a paz, a saúde e muitas outras realizações. O conhecimento e a aplicação destas leis remetem ao contexto de que acontecimentos simples podem ser entendidos como fatos que deveriam acontecer, independente de tempo e espaço e, que se assim percebidas, contribuem para uma harmonia e menor impacto negativo sob as pessoas.

Quatro, são as leis indianas da espiritualidade deixadas pelos sábios indianos que levam a reflexão e, porque não dizer, provocam mudanças se aplicadas como práticas ao longo da vida.

A primeira lei diz que, "a pessoa que vem é a pessoa certa." Independente da pessoa, do ser que cruzar em nosso caminho, seja amigo, conhecido, familiar ou aqueles 
que simplesmente são conhecidos por um único instante, é a pessoa que tinha que ali estar.Esta lei remete ao sentido da conexão e, esta deveria acontecer.

Segundo Marques (2021):

Sejampessoas boas ou ruins, todo ser que entra em nossas vidas faz algum tipo de transformação nela. Podem ser pessoas iluminadas, dispostas a compartilhar conosco os seus valiosos ensinamentos, mas também podem ser pessoas que nos prejudicam, o que nos ensina a como não agir e a como não ser. De um jeito ou de outro, há sempre um aprendizado, desde que ajustemos o nosso olhar para identificá-lo.Os companheiros, amigos, familiares e pessoas que nos fazem o bem são sempre fontes de amparo, de afeto e de força. Em contrapartida, aqueles que nos fazem o mal têm o objetivo de nos ensinar a agir de forma diferente deles, desenvolvendo também a paciência e a resiliência.

Desta maneira, independente da relação ou do encontro acontecer positiva ou negativamente, não haverá um tempo perdido, mas sim um propósito que pode proporcionar a felicidade ou o aprendizado para a maturidade, para se tornar alguém mais forte e mais sábio.

A segunda lei indiana, fala que se algo aconteceu, "aconteceu exatamente o que poderia ter acontecido.” Esta é a verdadeira lei da aceitação.Aceitar o bem e o mal, o bom e o ruim, sonhos realizados e sonhos frustrados, vitórias e fracassos sem ficar se martirizando com mágoas, fatos que poderiam ter dado certo, algo que poderia ter acontecido ou justificando ações que poderiam ter ocorrido, tendo plena convicção de que a vida continua e que um futuro melhor e mais feliz sempre pode ser planejado e estar em constante construção.

Marques (2021) afirma:

Assim como não acreditam em coincidências, os indianos também questionam muito o conceito de arrependimento. Para eles, o nosso destino já está definido, e todos os acontecimentos já estão traçados.

Se algo negativo aconteceu na vida de um indiano, ele sabe que não vale a pena pensar que poderia ter feito algo de diferente, pois o que está feito, está feito. Nada poderia ter sido mudado.

Segundo a tradição indiana, acontece conosco exatamente aquilo que é preciso que aconteça. O problema é que nem sempre os fatos são positivos. Por isso, é preciso encarar as dificuldades e os desafios como fontes de sabedoria. Não devemos pensar "por que isso tinha que acontecer comigo?", mas "o que posso aprender com isso que aconteceu?".

Diante desta visão, ao invés de lamentações, o que deve existir é a gratidão, por tudo, porque de alguma forma houve um aprendizado, houve uma nova experiência que trouxe um aprendizado para a pessoa que viveu determinada situação.

Já a abordagem trazida na terceira lei da espiritualidade diz que "toda vez que se iniciar algo, este será o momento certo.” A crença de que tudo tem hora para ocorrer e de 
que cada pessoa tem seu tempo, remete a compreensão de que ninguém está atrasado ou adiantado para iniciar algo.

Esta lei transmite o contexto da eternidade e vida espiritual.

Lopes (2013) explica que:

Se a vida espiritual não fosse eterna, esta lei não faria qualquer sentido, pois, quando um ser estivesse muito próximo do seu fim, próximo de sua total aniquilação, haveriam muitas coisas para as quais não seria o momento certo de dar início. Principalmente projetos de desenvolvimento interior, pois no caso de projetos materiais, se um homem começar em sua última semana de vida algo que outros possam dar sequência, ainda assim terá valido a pena para quem herdar o projeto.

Entende-se que nunca é tarde demais para dar início a um projeto, a uma nova etapa, sejam estes profissionais, pessoais, sociais, espirituais ou qualquer outra. Tudo chega no momento certo, na hora em que a pessoa estiver melhor preparada, fazendo desta maneira, que não hajam comparações entre uma ou outra pessoa, pois o tempo e a história que cada pessoa possui, é única.

A quarta e última lei da espiritualidade ensinada pelos sábios indianos fala que "quando algo acaba, acaba." Assim como tudo tem o momento certo para iniciar, também tem sua hora de terminar. Talvez esta seja a lei mais difícil de compreender, de se colocar em prática, pois é a lei do desapego e, segundo Lopes (2013):

É preciso aprender a deixar pra trás o que passou e olhar para o futuro com esperança, sempre atento à corrente de novas possibilidade que a vida está constantemente jorrando a todo o momento. É incrível como somos apegados a muitas coisas, tanto as boas como as ruins.

Ficamos apegados por tudo aquilo que era bom e que acabamos perdendo por algum motivo, mas também ficamos apegados aquilo que aconteceu de ruim, e que, apesar de já ter passado, fazemos constantes demonstrações de apego quando lamentamos o leite derramado, choramos o sofrimento sentido, lembramos e sentimos raiva por quem nos fez mal, culpamos o passado pelo que se tornou o nosso presente, tudo isso são formas de apego.

O entendimento e a reflexão que esta lei provoca é que tudo na vida possui um ciclo e, que este, ao se fechar, é preciso dar prosseguimento, vivenciando novos aprendizados, novas experiências, adquirindo novos conhecimentos, pois, o que era para ser aprendido com o ciclo que se encerra, foi devidamente cumprido. Pode-se entender ainda, que até mesmo a vida na terra tem um ciclo que, uma hora ou outra, irá se encerrar e, que a vida continuará em outras dimensões.

Desta maneira as quatro leis espirituais da Índia ofertam ensinamentos sem dificuldades, que podem ser vistos como relativamente simples, porém complexos, se abrangidos por falta de vontade ou falta de gestão emocional para cumpri-los, mas que colaboram com grandes 
experiências para a condução da vida com resiliência, paz, aceitação, desapego, paciência, empatia, conexões e felicidade.

\section{PASSADO, PRESENTE E FUTURO}

O tempo sempre foi e continua sendo tema de debate em todos os assuntos das pessoas seja ele por trazer a lembrança do que aconteceu, seja para discutir momentos que estão sendo vividos e enfrentados ou ainda para tentar imaginar ou planejar o que ainda está por vir.

Deste feito, porém, o tempo envolve mais do que apenas contar sobre um evento que aconteceu, tratar do que vem acontecendo ou planejar o que se pretende fazer. Este provoca em algumas pessoas sensações que despertam impactos diferenciados, dos quais podem impedi-las de ter uma vida vivida de maneira plena e saudável, causando, de certa maneira, a infelicidade, a dor ou angústia.

O passado vem a ser a parte do tempo que compreende o que passou, ou seja, aquilo que aconteceu em um período de tempo anterior ao tempo presente. Este por sua vez, não pode ser modificado ou alterado, tornando-se lembrança, uma memória que não deveria causar danos no momento presente.

Porém, para muitas pessoas, o passado torna-se tão presente que provocam dores profundas, causando perturbações que levam as mesmas perder a essência da vida no presente. $\mathrm{O}$ excesso de passado provoca a doença da depressão, que prende a pessoa em uma profunda tristeza, fazendo com que se não houver ajuda, pode levar a pessoa a sintomas extremos.

O futuro, por sua vez, é o período de tempo compreendido por aquilo que ainda não aconteceu, o momento que está por vir, trazendo fatos, experiências e aprendizados novos. Este deveria ser planejado sem causar tantas sensações nas pessoas, afinal de contas não se sabe ou não se tem certeza alguma de como será o amanhã.

Apesar de existir algumas ciências que tentam desvendar aquilo que está por vir, até hoje ninguém conseguiu, verdadeira e concretamente, dizer o que irá ocorrer no dia de amanhã. Mesmo assim, muitas pessoas sofrem por aquele excesso de futuro, sendo acometidas, segundo os especialistas, por uma ansiedade que provoca perturbações em várias áreas da vida, impedindo, também as pessoas de viverem melhor. 
No entanto, existe o período de tempo que deve ser considerado como seu próprio nome o define, o presente. Este sim é o tempo de aproveitar, pois é o tempo que se tem, é o único momento que se pode fazer algo, que se pode viver e realizar agora. A grande questão que envolve este período de tempo é o de que o tempo não pára e continua a fluir constantemente sem pausar, tornando-se impossível marcá-lo, pois, para cada intervalo de tempo que passa, transforma o presente em passado,caracterizando o presente como sendo constante e infinito.

Então o que resta é fazer valer a pena cada um dos minutos que se vive neste período de tempo, porém com certa cautela para que este tempo não se torne o grande problema da vida nos tempos contemporâneos, que é o estresse. Manter hábitos saudáveis é fundamental para que se encontre uma vida saudável, com qualidade e feliz.

Portanto, o passado deve ser entendido como um contexto que proporcionou aprendizado e evolução, fornecendo subsídios para nortear um amadurecimento das decisões de presente e futuro. O futuro precisa ser compreendido com o tempo que irá provocar um certo desejo de que este chegue, de deixar expectativas saudáveis, sem angústias para o que vai acontecer, porém que pode vir a ser um ciclo incógnito.

Já o presente é o tempo que precisa ser vivido, curtido, aproveitado e sabiamente desfrutado com a segurança e a maturidade proporcionada pelo aprendizado do passado. Assim considera-se, que se bem compreendido, o que se tem, na verdade, é só este momento de agora e nada mais.

\section{O AUTOCONHECIMENTO}

Constantemente o ser humano é instigado a falar de si mesmo, seja numa relação que se inicia, seja em uma entrevista de emprego, cadastro de currículo ou em discussões familiares e entre amigos, pois este é um assunto que sempre provoca curiosidades. Compreender o comportamento humano, seja este o próprio ou do outro, para descobrir o que o motiva, quais são os sonhos, os desejos e ter a possibilidade de ficar mais "íntimo", de certa maneira aproxima, faz com que haja maior conexão entre as pessoas.

Falar em autoconhecimento remete ao fato de um indivíduo saber sobre suas emoções, suas motivações, seus pontos fortes, seus pontos fracos, é conhecer a si mesmo de tal maneira que o mesmo possa exatamente buscar aquilo que lhe for melhor para levar uma vida saudável e feliz. 
Para Boechat (2008, p.I62), ...a tarefa de cada um de nós é procurar respostas dentro do microcosmo do processo de conhecimento (individuação, para a psicologia analítica) de cada um para produzir transformações no microcosmo da convivência das famílias, das sociedades, das cidades, das culturas, e mesmo da espécie humana.

A chamada individuação comentada pelo autor é o autoconhecimento. Assim, o mesmo autor comenta que o processo de individuação é o eixo teórico do pensamento de Jung e descreve o processo pelo qual cada indivíduo vem a ser o que realmente é (BOECHAT, 2008).

Por sua vez, Edinger (2004, p.33) diz que esse é um processo que vai se desenvolvendo aos poucos. Todos nós começamos identificados com o ambiente e com as pessoas que se encontram nele. Diante deste pensamento, subentende-se que o meio influencia cada pessoa inserida nele e, que o autoconhecimento vai se formando a partir de opiniões e observações de quem também é pertencente ao mesmo meio.

Por isto, talvez, seja mais fácil falar ou caracterizar o outro do que a si mesmo e, que a opinião alheia seja tão importante e impactante no comportamento humano. Mas o processo de autoconhecimento não é fácil, tornando-se, as vezes, algo doloroso, pois, faz com que o indivíduo faça uma análise de todos os processos de sua vida, de todas as suas características, que volte seu olhar para si mesmo de maneira analítica e reflexiva.

Edinger (2004, p.35) diz que o processo de autoconhecimento (individuação) é uma tarefa para a vida toda, e só pode ser alcançada quando uma quantidade significativa de energia é aplicada a ele. Encarar a realidade, em certos casos, torna-se uma grande e infindável batalha.

Sun Tzu, em sua obra A arte da Guerra já dizia:

Se você conhece a si mesmo não precisa temer o resultado de roo batalhas. Se você se conhece, mas não conhece o inimigo, para cada vitória sofrerá também uma derrota. Se você não conhece nem o inimigo, nem a si mesmo, perderá todas as batalhas".

Desta maneira, autoconhecimento acontece no momento que é propiciada a oportunidade de quebra de paradigmas, entenda-se estes paradigmas como modelos mentais que são formados ao longo da vida, decorrentes de experiências vividas e as várias situações que ocorreram e que ficam armazenados na mente, permitindo reflexões e até mudanças de atitudes decorrentes destas análises e destas quebras. 
Portanto, permitir conhecer a si mesmo é um processo de contínua aprendizagem que colabora para uma vida de evolução (como ser humano), entendimento dos verdadeiros valores que se possui, percepção que é preciso ser único e não aquilo que o meio externo mantém e exige como modelo, ressignificação e, desta forma encontrar a felicidade, pois, esta também depende e está diretamente ligada e conectada às escolhas que são feitas, interpretação de fatos e decisões emocionais e racionais tomadas diariamente que definem resultados e comportamentos.

\section{O DIREITO DE ERRAR}

Nem sempre o que foi planejado irá sair exatamente de acordo com cada detalhe premeditado. É neste quesito que muitos são julgam ou recebem julgamentos desnecessários, provocando dores, mágoas e até tendo como conseqüência a infelicidade.

Ninguém está livre de uma hora ou outra cometer uma falha, um deslize, afinal de contas, todos são humanos. O grande peso neste quesito é a representatividade e o significado que são dados por um erro cometido, o julgamento envolvido $e$ as conseqüências que envolvem uma falha, que não estava prevista.

Moraes (2020), afirma que compreender o direito do outro de errar é também entender o próprio direito de cometer falhas e que todos possuem defeitos, por isso é importante ter empatia pelo seu companheiro.

$\mathrm{O}$ ato de cometer falhas e aceitar o direito do outro de errar é humanamente natural, por isto a necessidade de perdoar deveria ser normal, afinal, a impossibilidade de alcançar a imperfeição faz parte da vida humana, porém muitos indivíduos não se dão e, nem ao outro este direito, por quererem sempre alcançar um objetivo, uma meta ou realizar algo sem o mínimo de falhas.

É aí que o erro acaba por provocar julgamentos, críticas, imposições, fazendo que a própria pessoa sinta-se atingida de forma negativa, impedindo que haja até mesmo um outro estado emocional para buscar uma solução, provocando medo, vergonha, inibição e tantas outras sensações negativas que paralisam os sentidos positivos.

Ter a compreensão de que o direito de errar de todas as pessoas é algo natural e normal, assim como de cometer falhas e saber que ninguém é perfeito, é uma necessidade do ser humano e que não há nada de errado nisto. Nem sempre se pode acertar, seja em ambientes familiares, sociais, profissionais, relação com amigos e mais. As vezes é 
tentando acertar que os erros acontecem. Em quase todas as vezes que um erro impactante acontece, há uma intenção positiva.

É preciso compreender que independentemente de qualquer ação, atividade ou qualquer outra coisa, as relações são formadas pela interatividade entre pessoas, entre seres humanos e, como é dito, "errar é humano".

É imprescindível saber que, embora o ato de errar seja um direito, o que não pode ocorrer são atos de irresponsabilidades, em querer sair executando ações de qualquer maneira ou fazendo tudo que achar viável, pois, independente do que é feito em qualquer ambiente, deve ser pautado em ética, moral, coerência e responsabilidade e, se isto ocorrer, ter em mente que em uma outra ocasião não será repetido.

\section{SER OUVIDO NA ESSÊNCIA}

Falar e ter a certeza que se está sendo ouvido e compreendido de acordo com aquilo que se pretende comunicar exatamente, é uma grande necessidade que impacta no sentir-se bem, no acolhimento, na capacidade de saber que há representatividade no processo comunicacional.

Ser ouvido na essência vai além da dedicação de prover um tempo para que uma outra pessoa fale, é permitir uma compreensão com aquilo que se pretende explanar, é ter atitude aberta e até mesmo um processo de autocura, porque permite avaliar e entender o que realmente vem sendo expresso sem tirar as pré conclusões e julgamentos desnecessários de uma fala qualquer.

É humanamente necessário ter com quem compartilhar algo e ser realmente ouvido, compreendido, respeitado, acolhido e não receber críticas ou julgamentos. Ser ouvido na essência representa não receber condenações desnecessárias. Ter com quem compartilhar um momento, uma ocasião, uma realização e que este alguém, realmente preste atenção e sinta aquela emoção que se quer transmitir, é algo que precisa ser muito valorizado.

Nobre (2013) corrobora que:

Há momentos que, na verdade, não queremos a resposta pronta para os nossos problemas, mas estamos somente procurando alguém que demonstre interesse no que estamos querendo dizer. Não queremos ser julgados e mal interpretados por nossas palavras, mas sentimos a necessidade de encontrar alguém que tenhamos liberdade de conversar e que nos entenda. 
Porém, ter com quem contar, com quem compartilhar, fazendo com que esta pessoa sinta emoções semelhantes ao ouvir algo e que esta preste atenção de verdade diante do que está sendo dito é algo valioso e raro de encontrar. Mas quando esta pessoa existe, ela consegue transmitir um bem tão grande para quem está sendo o comunicante, que cria relações de confiança, reciprocidade, tocando fundo o ser, que passa a sentir-se valorizado e consequentemente colaborando para o bem-estar e sentir-se bem.

É necessário, antes de falar, saber ouvir e, buscar ser ouvido como meio de compreensão, empatia, valorização e respeito a si próprio e ao outro. Isto proporciona melhores relacionamentos e conexões que contribuem para bons momentos.

\section{A NECESSIDADE DE PERTENCER}

Integrar-se a um grupo, ter amigos, fazer parte de um contexto social sempre foram necessários para as relações de pertencimento de uma pessoa a um grupo, uma tribo, uma sociedade. As relações são as mais variadas para que isto ocorra, seja em casa, com familiares, na igreja, no clube de fim de semana, no grupo do futebol e tantos outros. Isto transmite uma sensação socialmente boa de integração e conexão, provocando diversos tipos de reflexos na vida do ser humano.

Tudo isto acontece porque há o sentido de ser aceito e não unicamente somente estar participando de um momento qualquer e, isto colabora para que as pessoas tenham reflexos positivos e sensações boas em sua vida.

Diante disto, Moraes (2020) afirma que:

A presença também pressupõe coerência entre o que dizemos e aquilo que pensamos, nossos valores e crenças. Para estarmos presentes, além de estarmos verdadeiramente interessados na conexão, na interação, no que o outro tem a dizer, temos de acreditar naquilo que dizemos, sermos sinceros. E para isso, é preciso estar disposto a estar vulnerável a ponto de expressar-se verdadeiramente. É preciso também acreditar em suas habilidades e capacidades e querer expressálas. Presença, portanto, é antes de tudo, aceitar-se e aceitar o outro, sendo capazes de sermos nós mesmos e permitindo que o outro também se mostre tal como é.

O sentido de estar presente deve, neste contexto, ser entendido como não ser preciso mudar de comportamento, não ser preciso alterar a identidade que possui, conseguir ser autêntico diante de um grupo e tendo uma sensação de plenitude.

Esta convivência colabora para uma vida de relacionamentos que estabelece uma relação de coletividade, fortalecendo a pessoa e sua auto-estima, satisfazendo o sentido de pertencimento, ao tempo em que os sentidos de conexão produzidos pelo cérebro, 
corroborados pelas sensações de bondade existente, deixam as pessoas com sentimentos de integração, facilitando o enfrentamento de situações difíceis, tornando a vida mais leve e flexível.

Portanto, esta necessidade, cada dia mais importantes, pode refletir o quanto uma pessoa precisa manter contato, sentir-se amada ou aceita na sociedade para que venha transformar as relações entre ela mesma e com os outros, entendendo que experiências compartilhadas podem suavizar os contextos que muitas podem apresentar.

\section{A NECESSIDADE DE SER AMADO, RECONHECIDO}

Não se sentir rejeitado, demonstrar e receber afeição, ter a capacidade de transmitir e receber amor sem ter que pagar por isto ou sentir um sentimento de dívida, são necessidades recorrentes do ser humano.

É fato que as pessoas, independente de suas idades, tornam-se mais felizes e mais seguras para desenvolver habilidades e talentos quando possuem apoio ou alguém para caminhar ao seu lado, além de também terem a quem recorrer em caso de alguma adversidade.

Segundo Bowlby (2002), com efeito que, não somente quando crianças, mas também quando adultos, percebemos a pessoa amada como "mais forte e mais sábia". É neste contexto que a busca constante por relacionamentos, a necessidade de pertencer, ser aceito, amar e ser amado complementam-se entre si, relacionando-se diretamente ao comportamento, ao emocional e até mesmo ao físico das pessoas.

Porém esta necessidade pode provocar determinados traumas e trazer impactos que impedem as pessoas de terem um maior bem estar, porque sempre precisarão, sentir-se amadas ou "aprovadas". Diante disto Cruz (2018), diz que a primeira coisa que acontece quando evitamos constantemente a desaprovação é a perda da autoestima, deixamos de nos agradar para dar lugar aos pensamentos de outras pessoas em nossa vida. E ainda complementa, afirmando que uma pessoa que tem necessidade de aprovação torna-se passiva em suas opiniões e decisões. Sua vida passa a ser direcionada através dos olhos de outras pessoas. Dificuldades em dizer não, em contrariar a opinião de outra pessoa. (CRUZ, 2018)

Neste sentido, percebe-se que embora o sentimento de ser amado, amar e transmitir reciprocidade pode trazer conseqüências por duas vertentes, seja positiva ou 
negativa, é necessário que haja um equilíbrio e uma aceitação pessoal, primeiramente, com amor próprio, auto-estima e assim, posteriormente, procurar união e aproximação em relações diversas e conexões com sentimentos positivos, passando por valorização, reconhecimento e afeto, impedindo que haja infelicidade ou energias negativas.

O fato principal neste universo de relacionamentos é o de que é fundamentalmente importante o ser humano estar de bem consigo mesmo, primeiramente amando-se, aceitando-se, para que posteriormente ele possa cultivar uma boa relação com o outro, amando e sentindo-se amado e satisfazendo sua necessidade.

\section{A AUTOMOTIVAÇÃO E A PIRÂMIDE MASLOW}

Antes de falar de automotivação é necessário entender que a motivação é algo, uma força interior que acaba se modificando diariamente de acordo com as diversas experiências que vão direcionando as pessoas a alcançarem aos seus objetivos e metas de vida. A motivação também está ligada à satisfação das necessidades.

Segundo os autores Motta; Vasconcelos (2006), com base nos estudos de Maslow, que hierarquizou as necessidades humanas, independente de preocupações, todos os seres humanos tem necessidades que estão ligadas ao ego, ao desenvolvimento pessoal, a aprendizagem e a autorrealização. De acordo com a pirâmide elaborada por Maslow, o sujeito só estará motivado quando conseguir satisfazer todas as necessidades, respeitando sua hierarquia.

Então, segundo a teoria, na base da pirâmide estão todos os fatores fisiológicos ou de necessidades primárias, como o ato de comer, poder dormir, beber. Este primeiro nível, geralmente é o mais fácil de ser suprido, principalmente quando há algum suporte ou com quem contar.

O segundo nível na escala piramidal é caracterizado pela segurança, representado por um bom trabalho, onde a pessoa possa ter garantido seu sustento, uma boa residência, um asilo ou resguardo, onde o indivíduo possa sentir-se seguro e abrigado.

As necessidade sociais são representadas pela importância de haver ou manter relacionamentos, sentimentos de proximidade, de afeto, de amor, boas conexões, relações harmoniosas para se sentirem incluídas no contexto social, e estão indicadas pelo terceiro nível da pirâmide. Importante ressaltar que para muitas pessoas, sempre acontece um salto do primeiro para o terceiro nível da pirâmide e, em determinado momento a lacuna 
deixada por este salto, acaba provocando um espaço não preenchido que exigirá, hora ou outra, a necessidade de retornar para o segundo nível, a fim de satisfazê-lo e cumprir com o equilíbrio da pirâmide e motivar-se a seguir.

O próximo nível apresenta as necessidades de estima, expressas pela busca de reconhecimento pessoal e dos outros, motivando sempre as pessoas a buscarem, por vários meios alcançar tal reconhecimento, tal status e auto-estima. São estes sentimentos de alto estima que podem automotivar as pessoas à buscarem sempre mais, a não pararem, sem que haja avaliação de esforços, nem conseqüências para tal satisfação da necessidade, doa a quem doer.

Por último e, talvez para muitos indivíduos a maior conquista e alcance da felicidade, o nível da autorrealização que considera que a motivação será plena se todos os demais níveis tiverem sido alcançados e complementados por este.

Diante disto, pode-se indicar que ao satisfazer uma necessidade, o indivíduo vai ficando motivado a buscar sempre mais. Segundo Robbins (2006), de acordo com a teoria de Maslow, para motivar alguém é preciso saber em que nível da hierarquia a pessoa se encontra no momento e focar a satisfação naquele nível ou no patamar imediatamente superior.

Desta forma, entende-se que a motivação e a automotivação estão conectadas e diretamente ligadas ao autoconhecimento, que proporciona saber exatamente as necessidades que precisam ser satisfeitas segundo o objetivo de cada indivíduo, complementando-se bem, tornando-se, independente de vida pessoal ou profissional, uma importante função para o alcance e concretização do encontro do bem estar, da plenitude e da realização intrínseca que leva o indivíduo ao encontro da felicidade.

\section{O PERDÃO}

Desde sempre e por diversas gerações, muitos indivíduos trazem consigo determinadas dores, mágoas e cicatrizes que, vez ou outra, acabam por machucar. Seja por acontecimentos que marcaram fortemente a vida em um tempo passado, fazer com que estes representem apenas um aprendizado é um grande desafio, fato que acaba por intervir e atrapalhar de se ter uma vida mais leve.

Por acreditarem que manter vivo pensamentos, mágoas ou outros fatos que marcaram negativamente a vida e ficarem alimentando uma certa expectativa de vingança 
e não conseguir superar, seja por não querer ou até mesmo por nem tentar, é que o ser humano acaba por viver com uma dor que o impede de refletir, crescer, aprender e superar, de cabeça erguida, o fato ocorrido.

Quando estes pensamentos são disfuncionais e não adaptativos, influenciam negativamente as reações emocionais, comportamentais e fisiológicas da pessoa que reponde a situação de acordo com seus padrões de pensamentos. (BECK, 1997).

Assim, para evitar reações comportamentais, emocionais e até fisiológicas que impactam de maneira negativa e não mereçam tanta ênfase na vida presente dos indivíduos, o melhor caminho é o perdão, que libera a pessoa de algo que a machuca e a torna prisioneira de suas dores e mágoas.

A grande questão que envolve o perdão é livrar-se verdadeiramente destas amarras que deixam as pessoas com marcas vivas em sua mente ou corpo, seja por crença, orgulho ou outro fator impeditivo. Oliveira (2013) cita que, muitas vezes não perdoamos porque acreditamos que o perdão representa humilhação, fraqueza, vulnerabilidade, contribui para a injustiça, entre outras crenças.

Como para cada pessoa o fato vivido representa uma experiência que marcou sua vida, poupar-se de um sofrimento pode significar sentir-se inferior frente a quem lhe provocou grande dor, mantendo viva aquela situação que vez ou outra acaba por ferir novamente, tirando a paz, não deixando que a esperança e o otimismo se façam presentes.

Pode-se dizer que o perdão é a libertação do passado, pois foram situações que ocorreram lá atrás que marcam o tempo presente, demonstrando que neste período (o presente), ainda têm grande importância. E ainda, tais ocorridos podem interferir em um período que ainda nem chegou, pois, as amarras podem provocar barreiras impeditivas do planejamento futuro.

Diante do exposto Seligman (2012) expõe que o perdão é uma das atitudes que permite mudar o foco das experiências negativas e gerar emoção positiva e aumentar a satisfação do indivíduo, já que este enfraquece o poder que os acontecimentos negativos têm de provocar raiva e amargura, e permite reescrever a história e renovar a memória, transformando más lembranças em boas.

Percebe-se então que o perdão é uma ação que permite dar novo rumo na vida das pessoas, fazendo com que haja melhores atitudes, liberdade de pensamentos negativos, permitindo que, a partir do momento que o mesmo ocorre, o indivíduo passe a ter uma 
percepção diferenciada de todos os acontecimentos ocorridos e, de certa maneira venha praticar a gratidão e pensamentos positivos.

Oliveira (2013) afirma que ao conhecer o modo como sentimos (passado), pensamos (futuro) e vivemos (presente), podemos redefinir nossas emoções direcionandoas de maneira mais positiva.

Assim, o perdão pode ser um passo para ter uma vida mais harmoniosa, com novos planejamentos e um novo sentido, tanto no presente, quanto no futuro que está por vir, tendo a compreensão de que perdoar não significará concordar com o ato ocorrido de quem provocou uma ofensa ou algum mal, ou que ainda considerar que aquilo será esquecido, mas sim, o ato de perdoar é saber que o fato ocorrido não mais representará hostilidade que existia. $\mathrm{O}$ ato de perdoar faz bem para quem sofreu o mal e não para o ofensor.

\section{A GRATIDÃO}

Conceituar a gratidão como forma de reconhecimento por uma conquista ou uma oportunidade que surge, torna-se uma virtude que há muito discute-se.

Por longo período da história da humanidade, a gratidão está presente em muitas culturas, sendo percebida como um objetivo socialmente desejável e diferentes experiências e expressões são tratadas como aspectos básicos e desejáveis da personalidade humana (EMMONS; MCCULLOUGH, 2003).

Desde os primórdios a gratidão é abordada em tradições religiosas, trazida em textos, tratada em orações e sendo ensinada por vários atores de áreas sociais diversas. Também desde a antiguidade, muitos autores escreveram sobre a gratidão, apontando-a como uma das mais importantes virtudes e como um ingrediente necessário para a formação da personalidade moral (EMMONS, 2004).

Para muitos a gratidão é vista como uma função social e esta deveria ser lembrada constantemente como reciprocidade advinda das interações humanas, ou seja, o reconhecimento por aquilo que se obtém e que provoca a coesão social, pois, se percebe e cria relações entre pessoas. Algoe, Haidt e Gable (2008), em um estudo empírico, encontraram dados que indicam que a gratidão tem a função de promover e manter relacionamentos. A reciprocidade que a gratidão enseja - a mútua troca de favores - teria uma função de equilíbrio social. 
A gratidão pode ser vista sobre vários aspectos na evolução humana, destacandose a gratidão na psicologia, que utiliza uma ótica sobre a emoção, as atitudes, um traço de personalidade, a uma virtude moral e ética, um hábito ou uma resposta para regular um estado emocional, buscando o equilíbrio da vida.

Também a gratidão pode estar ligada a traços de personalidade, abordando que pessoas gratas são mais agradáveis e menos narcisistas (MCCULLOUGH et al., 200I). Sob este mesmo prisma, Baumgarten-Tramer (1938) sugere uma relação entre personalidade e gratidão: indivíduos com personalidade mais realista, ou avara, tenderiam a ter um senso de dívida mais proporcional ao favor recebido do que indivíduos com personalidade impulsiva, imaginativa e generosa, os quais tenderiam a ter um senso de dívida excessivo.

Em um ponto de vista da gratidão e o bem-estar subjetivo, que envolve sentimentos de gratidão, estes podem aumentar a resiliência, o bem estar, a saúde física e a qualidade da vida diária. Emmons e McCullough (2004) concluíram que pessoas gratas não apenas demonstram mais estados mentais positivos, isto é, mostram-se mais entusiásticas, determinadas e atentas, como também são mais generosas, cuidadosas e atenciosas para com os outros. Ainda, pessoas que se sentem regularmente gratas aos outros tendem a sentirem-se amadas e cuidadas (ANDERSSON; GIACALONE; JURKIEWICZ, 2007).

A gratidão também pode ser analisada pelo aspecto moral, sendo percebida como um afeto moral, vista desta forma como um comportamento moral que leva o outro em consideração. Também neste aspecto a gratidão é entendida como uma virtude moral, ou seja, sendo fundamentalmente a não necessidade de receber a gratidão de alguém que torna esta, uma virtude moral.

Outro aspecto aborda a gratidão como um sentimento interindividual, que consiste em uma ação individual repercutir sobre outros, ou seja, existindo uma ação de devolução, que inclui o material ou virtual.A ação pode ser de retorno material, quando transfere ou doa-se um objeto em agradecimento por uma ação recebida. Já a ação de retorno virtual acontece quando uma valorização positiva ou negativa de um agente qualquer ocorre dentro de uma chamada escala pessoal de valores, que pode ser compreendida como uma valorização, uma satisfação ou um sentimento de dívida surgida por uma benesse recebida, fato que instiga o sentimento interindividual fazendo-o aparecer. 
De qualquer forma, é preciso que haja uma elucidação cada vez maior ao sentimento de gratidão, que ainda deve andar acompanhada pela valorização da vida, pela habilidade de enfrentar e confrontar os desafios diários, de se potencializar, aprender, crescer e se desenvolver. Então, pode se entender o ato de ser grato como algo transformador para as pessoas como seres humanos, colaborando para um equilíbrio entre o ser físico, o ser espiritual, o crescimento, o convívio social e um caminho para o desenvolvimento de todos os aspectos formadores deste.

\section{A EMPATIA}

Empatia, amplamente utilizada em contextos sociais, teve origem no vocábulo grego "Empatheia", que se refere a ser capaz de valorizar os sentimentos ou opiniões dos outros, e até mesmo trazer paixão ou ser muito influenciado.

De maneira geral ela pode ser vista como uma habilidade socioemocional que cada indivíduo possui, ou ainda uma habilidade multidimensional, pois compreende forças afetivas, cognitivas e comportamentais de cada um. Entende-se a empatia não como uma capacidade que transmite uma aptidão natural, porém ela pode ser adquirida.

Segundo Hoffman (1987, I99I), a empatia está diretamente relacionada ao desenvolvimento de um senso cognitivo sobre a existência de outras pessoas, o qual, por sua vez, se encontra ligado ao processo de diferenciação do self. Em termos distintos, a empatia considera a existência do ser, levando em consideração a compaixão pelo próximo, sabendo das individualidades de cada ser, mas com relações interpessoais.

Para Decety e Jackson (2004), a empatia seria uma experiência fenomênica unicamente humana e teria bases evolutivas. Estas seriam compostas por elementos cognitivos (tomada de perspectiva, autoconsciência, reconhecimento e compreensão dos estados mentais das outras pessoas, etc).

Nesse sentido Hoffman (199I) afirma haver diferenças qualitativas nos componentes afetivos da empatia, fundamentalmente no que diz respeito à natureza da experiência subjetiva do observador e às motivações produzidas pelos sentimentos empáticos.

Sendo assim a empatia pode ser entendida como competência emocional, diretamente relacionada com habilidades e outras capacidades que os indivíduos possuem para manter um relacionamento interpessoal, de maneira individual, compreendendo a 
competência emocional social. $\mathrm{Na}$ ausência dessa habilidade, ocorre uma ruptura de competência que compõe ou deveria compor esse indivíduo. Em longo prazo, essa incompetência poderia contribuir para a construção de um repertório de comportamentos sem plena consciência ou capacidade de perceber os sentimentos de outra pessoa (VIEIRA, 2017).

Contudo a empatia não significa simplesmente se pôr no lugar do outro de uma maneira racional, ela é centrada em respeito e conexões de caráter emocional e pessoal de cada indivíduo. É por meio de contatos sociais, reconhecimento e interpretação de sentidos que as pessoas precisam aprender as limitações existentes, sejam racionais ou emocionais e os impactos que certas ações promovem no desenvolvimento afetivo de cada um, na identificação de emoções, no comportamento solidário e a empatia.

Portanto a empatia é compreendida, de outro modo, como a capacidade de considerar e respeitar os sentimentos alheios, de se colocar no lugar do outro, ou vivenciar o que a outra pessoa sentiria caso estivesse em situação e circunstância similar (SILVA, 2008). Considera-se neste ínterim, não fazer ao outro o que não seria bem sentido por si, caso estivesse em determinada situação.

No entanto ser empático é algo que nem sempre será fácil, mas que pode e precisa ser aprendido, principalmente relevando aspectos que se referem a julgamentos desnecessários, críticas individuais, preconceitos ou qualquer outra ação que não esteja relacionada a aceitação dos pares (julgador e julgado).

Ser empático não irá tornar uma pessoa equilibrada e feliz, mas certamente proporcionará mudanças que colaborarão para um melhor desenvolvimento das relações pessoais que incidirão em melhores relacionamentos e melhores conexões sociais.

\section{INTELIGÊNCIA EMOCIONAL E GESTÃO DAS EMOÇÕES}

Em tempos de mudanças constantes, desequilíbrio emocional, impactos psicológicos e muitos outros fatores que atingem diretamente o convívio e a vida física e mental das pessoas, conhecer as emoções, interpretá-las a fim de ter uma inteligência e uma gestão adequada destas, torna-se fundamental para encontrar uma qualidade de vida satisfatória.

As emoções estão diretamente ligadas ao bem estar, a satisfação, a insatisfação, o engajamento, a relacionamentos, autorrealização, dentre outras. Identificar as emoções e 
saber que tudo gira e está conectado nas ações que provém destas, tendo sempre uma conseqüência é um dos primeiros passos para trabalhar a inteligência emocional.

Nascido em 1946, Daniel Goleman, psicólogo e jornalista, tornou-se entre vários pesquisadores, referência como o principal pesquisador que se dedica ao estudo do conceito de inteligência emocional, o qual a define como uma capacidade de identificar nossos próprios sentimentos e dos outros, de nos motivarmos e gerirmos os impulsos dentro de nós e em nossos relacionamentos (GOLEMAN, 20II).

De maneira geral a emoção vem ser uma sensação que envolve reações e impulsos no corpo e mente do ser humano, sendo esta provocada por estímulos de diferentes naturezas e que acabam afetando diretamente as relações pessoais, interpessoais e profissionais de cada indivíduo.

Para o desenvolvimento da inteligência emocional é importante conhecer, pelo menos, cinco emoções básicas que provocam sensações diferenciadas no comportamento humano. A primeira delas é a raiva, definida como uma das emoções básicas que as pessoas possuem, sendo um sentimento de protesto, insegurança, timidez, obstáculo ou frustração, contra alguém ou alguma coisa, que se exterioriza quando o ego se sente ferido ou ameaçado, tendo como conseqüência um desequilíbrio psicológico que, em muitos casos pode trazer diferentes formas de reações, quase sempre negativas.

A segunda é o medo, caracterizado por uma reação emocional que deriva da interpretação de uma situação de perigo, algo que constitui uma ameaça para o bem-estar, tendo como consequência uma fuga, um alerta para a vulnerabilidade humana.

Outra emoção considerada básica é a tristeza que implica a maior negatividade. Essa emoção implica numa queda de ânimo, de vigor, de ousadia, além de uma redução considerável no nível de atividade cognitiva e de conduta. Apesar da má fama que essaemoçãotem, ela cumpre funções iguais ou mais importantes que as demaisemoções básicas, resultando em uma paralisação, falta de vontade de agir ou irritabilidade, em muitos casos.

Por outro lado a alegria, de todas as emoçõesbásicas, talvez seja a mais positiva. Está associada de forma direta com o prazer e a felicidade. Geralmente ela surge como resposta à uma conquista de alguma meta ou objetivo pessoal que progrediu ou frente à superação ou extinção de um estado de mal-estar, trazendo efeitos de aproximação, conectividade ou compartilhamento. 
O afeto considerado também uma das emoções básicas do ser humano, está associado ao estimulo do contato, da conexão interpessoal, promovendo proximidade, compartilhamento de boas ações, para uma realização ou satisfação de bem estar, fazendo com que haja maiores conexões entre as pessoas.

Entretanto o conhecimento das emoções básicas, é importante, pois,todas elas provém de algum tipo de estímulo, fazendo com que as pessoas desenvolvam vários tipos de reações, que podem ser sentidas de maneira positivas ou negativas.

Conhecer as causas e as consequências destas emoções será um grande passo para se ter inteligência emocional e fazer a gestão destas, pois, mais importante que ter a inteligência emocional e conhecer as emoções é fazer a gestão, identificando cada agente causador e buscando manter um autocontrole frente as diversas situações.

Em todo e qualquer ato as emoções ao serem identificadas pelo cérebro humano, de várias maneiras, primeiramente, são sentidas, o que é considerado como uma ação que sempre se refere a alguém ou a alguma situação, mas com uma variável, porque possui uma intensidade agradável ou desagradável, de acordo com cada pessoa. As sensações são produzidas na superfície do corpo e em seu interior e seus receptores são o que chamamos de sentidos. A intensidade e as reações no corpo humano podem ocorrer de diversas maneiras, variando de pessoa para pessoa, refletindo o impacto causado pela percepção em um primeiro ato.

O importante neste sentido é saber como expressar as emoções das mais diversas formas, o que pode significar um ato de mudanças impactantes nas relações e comportamentos intra e interpessoais, refletindo o quanto uma pessoa pode ser capaz ou não de controlar a energia produzida por um sentimento inicial.

Desta forma a gestão de todos os sentidos e reações que uma pessoa possui, deve acontecer principalmente por meio de autoconhecimento, autocontrole, autorregulação comportamental, primando por uma estabilidade emocional e consequentemente a gestão das emoções.

\section{CONSIDERAÇÕES FINAIS}

Então, falar de felicidade é falar de muitos elementos que interferem no dia a dia de cada pessoa, entendendo e tendo plena convicção que cada um sofre impactos, significados 
e uma representatividade diferente para si, de acordo com aquilo que realmente acredita ser felicidade ou tornar-se feliz.

Os vários conceitos aqui abordados trouxeram uma visão de que, na verdade não há um conceito definido e finalizado sobre felicidade, mas que este apresenta-se em constante construção, tornando-se uma busca perene pelos seus efeitos e o quanto isto representa para cada pessoa, de maneira individual.

O conhecimento expresso nos significados e na influência das leis da espiritualidade na visão indiana, sobre as pessoas, colaboraram para provocar reflexões de comportamentos, aceitações e o quanto as mesmas podem prover uma vida com maior equilíbrio e menor apreensão que as vezes paralisam indivíduos em vários níveis, proporcionando entender que é possível viver uma vida mais leve e não ficar preso a questões que podem ser consideradas por outros pontos de vista.

A representatividade do tempo na vida das pessoas, considerando o passado, o presente e o futuro, demonstrou o quanto os vários ocorridos tem importância e que merecem ser, ao seu tempo, deixados cada um em seu lugar e o que realmente importa de verdade, é o momento que se tem hoje, pois nenhum outro pode ser alterado ou ainda ser vivido.

A abordagem sobre o autoconhecimento apresentou a necessidade de mudar os modelos mentais existentes, criados ao longo de várias experiências vividas, e que continuamente precisam ser revisados por reflexões e auto-análises comportamentais, emocionais e tantas outras que formam o perfil individual de cada pessoa.

As necessidades apresentadas ao longo deste artigo foram essencialmente descritas como elementos que, segundo as fontes pesquisadas, compõem o caráter e impactam em comportamentos e na formação pessoal de cada pessoa, porém, se forem melhores compreendidas e cumpridas, respeitando os vários compostos que envolvem cada uma, podem colaborar para uma vida com mais harmonia, flexibilidade, melhores relacionamentos e equilíbrio.

A motivação, a automotivação, assim como o ato de perdoar, sentir gratidão e empatia, refletiram sobre estes elementos que fazem parte e compõem cada pessoa, porém que para muitos ainda não são praticados. Foi possível descrever e apresentar, conforme algumas fontes, as relações que cada uma tem com bem estar, sentir-se em paz, com melhores comportamentos, questões interpessoais e intrapessoais e, que tudo isto de 
alguma maneira positiva será determinante para o desenvolvimento do indivíduo como ser humano.

Claro que não existe uma fórmula mágica para tudo acontecer como se fosse um conto de fadas, sem levar em conta as múltiplas variantes que interferem na vida cotidiana, mas que certamente, pequenas ações puderem ser cumpridas, podem trazer resultados diferenciados para o viver de cada pessoa.

Como as emoções são componentes essenciais da vida humana, a inteligência emocional e a gestão de cada uma delas, torna-se fator de sobrevivência saudável, agradável e para compreensão de como expressar cada uma delas, nas mais diversas situações. E, em tempos onde é necessário manter uma estabilidade emocional, entender as causas e as conseqüências que uma emoção provoca na pessoa em determinada ocasião, é fundamental para a manutenção do controle e a estabilidade comportamental, o autoconhecimento, o autocontrole, a autorregulação das ações, a empatia e outros elementos e sensações que compõem o ser humano.

Diante de todo o exposto entende-se que a felicidade é uma sensação muito subjetiva que pode estar ligada a traços de personalidade, comportamento, temperamento e postura, podendo ser influenciada por aspectos intrínsecos ou extrínsecos, que se coloca como um fator de constante investigação e que pode influenciar bastante nos níveis de desenvolvimento pessoal ou até mesmo profissional.

Sabe-se que ainda existem muitos elementos subjetivos que levam as pessoas a terem diversos comportamentos e ações, compreendendo a felicidade à sua maneira e que muitos outros estudos e abordagens podem ser desenvolvidos em torno desta temática, futuramente, trazendo novos conceitos e envolvendo o bem estar, a satisfação, novas teorias de como promover uma vida plena e feliz, oportunizando esta análise por outros pontos de vista e conclusões das pessoas.

De maneira geral os conceitos aqui apresentados proporcionaram entender, um pouco, dos impactos e dos significados que cada um dos elementos pode ter sobre comportamentos, atitudes e na vida de cada pessoa, além de colaborarem para o alcance do objetivo principal proposto, demonstrando os pontos chave que compõem a chamada felicidade.

Portanto, felicidade pode depender de um conjunto de elementos e fatores que podem se adequar a comportamentos, a atitudes ou relações, bem como pode ser descoberta 
de maneira simples e objetiva. O importante é que ela, em dado momento acaba por existir, fazendo com que o indivíduo por si só tenha esta percepção e curta o momento, desfrutando o instante e continuando a trilhar o seu caminho em busca do encontro com a felicidade.

\section{REFERÊNCIAS}

ABBAGNANO, Nicola - "Dicionário de Filosofia", Martis Fontes, São Paulo, 2000.

A CONSTANTE busca pela felicidade, 2021. Disponível em: https://www.diariodaregiao.com.br/vidaearte/comportamento/a-constante-busca-pelafelicidade-I.519II. Acesso em II de novembro de 202I.

ALGOE, S. B.; HAIDT, J.; GABLE, S. L. Beyond reciprocity: Gratitude and relationships in everyday life. Emotion, v. 8, n. 3, p. 425-429, 2008.

ANDERSSON, L. M.; GIACALONE, R. A.; JURKIEWICZ, C. L. On the relationship of hope and gratitude to corporate social responsibility. Journal of Business Ethics,v. 7o, p. 40I-409, 2007.

ARISTÓTELES. Ética a Nicômaco. (Trad. do grego: Mário da Gama Kury). Brasília, Editora da Universidade de Brasília, 1985.

BARBOSA, P. S. C. Introdução ao estudo da felicidade segundo Aristóteles. Saberes: Revista interdisciplinar de Filosofia e Educação, v. I8, n. 2, 8 ago. 2018.

BAUMGARTEN-TRAMER, F. "Gratefulness" in children and young people. Journal of Genetic Psychology, v. 53, p. 53-66, 1938.

BERTI, Enrico - "No princípio era a maravilha", Loyola, São Paulo, zoı.

BECK, J. S. (1997).Terapia cognitiva: Teoria e prática(S. Costa, Trad.). Porto Alegre: Artmed (Obra original publicada em 1995).

BOECHAT, W. A mitopoese da psique: mito e individuação. Petrópolis, RJ: Vozes, 2008.

BOWLBY, John, 1907 -. Apego e Perda. A natureza do vínculo, a trilogia do apego. V.I. Tradução de Álvaro Cabral. $3^{\underline{a}}$ ed. São Paulo: Martins Fontes, 2002.

CORTELLA, Mário Sérgio. Felicidade é Sentir a vida vibrando. mariosergiocortella.com, I7 de fevereiro de 2021. Disponível em: http://mariosergiocortella.com/felicidade-e-sentira-vida-vibrando-num-abraco-mario-sergio-cortella/. Acesso em io de novembro de 2021. 
CRUZ, Cláudia. Necessidade de Aprovação: o sofrimento de querer agradar a todos. 2018. Disponível em: https://psicologiaacessivel.net/2018/o4/28/necessidade-de-aprovacao-osofrimento-de-querer-agradar-a-todos/. Acesso em I8 de dezembro de 2021.

DECETY, J., \& Jackson, P. L. (2004). The functional architecture of human empathy. Behavioral and Cognitive Neuroscience Review, 3(2), 71-1oo.

EDINGER, E.F. Ciência da Alma: Uma perspectiva junguiana. São Paulo: Paulus, 2004.

EMMONS, R. A. An introduction. In: EMMONS, R. A.; MCCUlLOUGH, M. E. (Org.). The psychology of gratitude. New York: Oxford University Press, 2004. p. 3-16.

; MCCULLOUGH, M. E. Counting blessings versus burdens: An experimental investigation of gratitude and subjective well-being in daily life. Journal of Personality and Social Psychology, v. 84, n. 2, p. 377-389, 2003.

FILHO, Clóvis de Barros. O que é felicidade segundo o professor Clóvis de Barros Filho. 202I. Disponível em: https://wocc.com.br/blog/o-que-e-felicidade-segundo-prof-o-clovisde-barros-filho/. Acesso em i8 de novembro de 2021.

FILOSOFIA e felicidade: o que é ser feliz segundo os grandes filósofos do passado e do presente, 2021. Disponível em: https://educacao.uol.com.br/disciplinas/filosofia/filosofiae-felicidade-o-que-e-ser-feliz-segundo-os-grandes-filosofos-do-passado-e-do-presente.htm. Acesso em io de novembro de 2021.

GERMER, Guilherme Marconi.A BUSCA DA FELICIDADE: NOSSO ERRO, ILUSÃO E EXISTÊNCIA FUNDAMENTAIS, SEGUNDO SCHOPENHAUER. $201 \mathrm{I}$

GOLEMAN, Daniel Inteligência emocional [recurso eletrônico] / Daniel Goleman; tradução Marcos Santarrita. - Rio de Janeiro : Objetiva, 2orı. recurso digital.

HOFFMAN, M. L. (1987). The contribution of empathy to justice and moral judgment. In N. Eisenberg, \& J. Strayer (Eds.), Empathy and its development (pp. 47-79). New York: Cambridge University Press

(1991). Empathy, social cognition and moral action. In W. M. Kurtines\& J. L. Gewirtz (Eds.), Handbook of moral behavior and development (pp. 65-87). New Jersey: LEA.

HOMEM não quer felicidade diz Nietzsche. 2021. Disponível em: https://universodafilosofia.com/2018/o2/homem-nao-quer-felicidade-diz-nietzsche/. Acesso em 12 de novembro de 2021.

KARNAL, Leandro. Lives do conhecimento Leandro Karnal fala sobre o processo de construção da felicidade, 2021. Disponível em:

https://www.unifor.br/web/saude/lives-do-conhecimento-leandro-karnal-fala-sobre-oprocesso-de-construcao-da-felicidade 
LOPES, Mateus. As 4 Leis da Espiritualidade ensinadas na Índia. mateuslopes.com, novembro de 2013. Disponível em https://www.mateuslopes.com/2013/II/as-4-leis-daespiritualidade-ensinadas-na-india/. Acesso em I2 de novembro de 202I.

MARQUES, José Roberto. As 4 leis da espiritualidade da Índia. 2021. Disponível em: https://jrmcoaching.com.br/blog/as-4-leis-espirituais-da-india/. Acesso em 8 de novembro de 2021.

MARÍAS, Julián - "A felicidade humana", Duas Cidades, São Paulo, i989.

MCCULlOUGH, M. E. et al. Is gratitude a moral affect? Psychological Bulletin, v. 127, n. 2, p. 249-266, 2001.

MORAES, Cláudio Riccioppo de. As quatro necessidades básicas da mente de um ser humano.2020. Disponível em: https://www.mundodomarketing.com.br/noticiascorporativas/conteudo/236033/as-quatro-necessidades-basicas-da-mente-de-um-serhumano. Acesso em I8 de dezembro de 2021.

MOTTA, Fernando C. Prestes; VASCONCELOS, Isabella F. Gouveia de. Teoria Geral da Administração. 3 ed. São Paulo: Pioneira Thomson Learning, 2006.

NEFF, Kristin. A Necessidade de pertencer: ficamos melhores quando percebemos a experiência humana compartilhada, 2017. Disponível em: https://papodehomem.com.br/anecessidade-de-pertencer-ficamos-melhores-quando-percebemos-a-experiencia-humanacompartilhada/. Acesso em I7 de dezembro de 2021.

NOBRE, Ariel. 2013. Necessidades básicas do ser humano. Disponível em: https://arielnobrecoaching.wordpress.com/2013/or/18/as-3-necessidades-basicas-do-serhumano/. Acesso em i6 de dezembro de 2021.

OLIVEIRA, Adriano (2013). A Fórmula da Felicidade. Retirado em 24/or/2013 do Portal da Psicologia Positiva, http://www.psimais.com/artigos.

OLIVIERI, Antonio Carlos. 2009.Filosofia e felicidade - O que é ser feliz segundo os grandes filósofos do passado e do presente.

REVISTA Voluntas: estudos sobre Schopenhauer- 2을 semestre 20II - Vol. 2 - № 2 ISSN: 2179-3786 - pp. I13-127. Acesso em i3 de novembro de 2021.

ROBBINS, Stephen P. Comportamento Organizacional. São Paulo: Prentice Hall, 2006.

SILVA, A. B. B. (2008). Mentes perigosas - O psicopata mora ao lado. Editora Fontanar, p.15-40

SKINNER, B.F. (1974). Sobre o behaviorismo. São Paulo: Cultrix 
SELIGMAN, Martin E. P. Florescer. Uma Nova E Visionária Interpretação Da Felicidade E Do Bem-estar. Rio de Janeiro: Editora Objetiva, 2012.

TZU, Sun. A arte da guerra / Sun Tzu; tradução de Sueli Barros Cassal. Porto Alegre: L\&PM, 2009.

VIEIRA, P. O poder da autorresponsabilidade: A ferramenta comprovada que gera alta performance e resultados em pouco tempo. São Paulo - SP: Editora Gente,2017. 